\title{
Characterization and Evaluation of Methane Oxidation Catalysts for Dual-Fuel Diesel and Natural Gas Engines
}

\author{
Donnie J. Worth $^{1}$ • Marc E. J. Stettler ${ }^{1,2} \cdot$ Paul Dickinson $^{1} \cdot$ Kieran Hegarty $^{1}$ • \\ Adam M. Boies ${ }^{1,3}$
}

Received: 23 June 2016/Revised: 12 August 2016 / Accepted: 14 September 2016 /Published online: 4 November 2016

(C) The Author(s) 2016. This article is published with open access at Springerlink.com

\begin{abstract}
The UK has incentivized the use of natural gas in heavy goods vehicles (HGVs) by converting to dual-fuel (DF) diesel-natural gas systems to reduce noxious and greenhouse gas emissions. Laboratory and on-road measurements of DF vehicles have demonstrated a decrease in $\mathrm{CO}_{2}$ emissions relative to diesel, but there is an increase in greenhouse gas $\left(\mathrm{CO}_{2} \mathrm{e}\right)$ emissions because of unburned methane. Decreasing tailpipe emissions of methane via after-treatment devices in lean-burn compression ignition engines is a challenge because of low exhaust temperatures $\left(\sim 400^{\circ} \mathrm{C}\right)$ and the presence of water vapor. In this study, six commercially available methane oxidation catalysts (MOCs) were tested for their application in DF HGV vehicles. Each MOC was characterized in terms of the catalyst platinum group metal (PGM) loading (both Pd and Pt), particle size, catalytic surface area, and Pd:Pt ratio. In addition, the washcoat surface area, pore volume, and pore size were evaluated. The MOC conversion efficiency was evaluated in controlled methane-oxidation experiments with varying temperatures, flow rates, and gas compositions. Characteristic-conversion efficiency correlations demonstrate that the influential MOC characteristics were PGM loading (both Pd and Pt), Pd:Pt ratio, washcoat surface area, and washcoat pore volume. With $90 \%$ methane
\end{abstract}

Electronic supplementary material The online version of this article (doi:10.1007/s40825-016-0047-x) contains supplementary material, which is available to authorized users.

Adam M. Boies

a.boies@eng.cam.ac.uk

1 Centre for Sustainable Road Freight, Department of Engineering, University of Cambridge, Cambridge CB2 1PZ, UK

2 Centre for Transport Studies, Department of Civil and Environmental Engineering, Imperial College London, London SW7 2AZ, UK

3 Department of Civil, Environmental and Geo- Engineering, University of Minnesota, Minneapolis, MN 55455, USA oxidation at less than $400{ }^{\circ} \mathrm{C}$ in DF HGV exhaust conditions, sample 1 had the highest conversion efficiency because of a high PGM loading $\left(330 \mathrm{~g} / \mathrm{ft}^{3}, 12,000 \mathrm{~g} / \mathrm{m}^{3}\right)$, a $5.9 \mathrm{Pd}: \mathrm{Pt}$ ratio, a high alumina washcoat surface area of $20 \mathrm{~m}^{2} / \mathrm{cm}^{3}$, and $74-\mathrm{mm}^{3} / \mathrm{cm}^{3}$ pore volume. Additional studies showed increased MOC conversion efficiency with decreasing gas hourly space velocities (GHSVs) and increasing methane concentrations.

Keywords Methane oxidation catalyst · Dual fuel · Heavy goods vehicles (HGVs)

\section{Introduction}

\subsection{Context}

Heavy goods vehicles (HGVs) are responsible for $16 \%$ of $\mathrm{CO}_{2}$ emissions in the United Kingdom's (UK) [1] transport sector. These vehicles are nearly all diesel fueled, but alternative fuels are being explored in anticipation of future regulations of HGVrelated $\mathrm{CO}_{2}$ vehicle emissions in the European Union [2]. Natural gas is a suitable option for reducing $\mathrm{CO}_{2}$ emissions, as methane (the primary component of natural gas) has a low carbon-hydrogen ratio, resulting in natural gas-producing lower $\mathrm{CO}_{2}$ emissions [3]. Investments are already being made to retrofit existing HGVs to be powered by a dual-fuel (DF) mixture of diesel and natural gas, such as the UK Government's investment of $£ 11.3$ million through the Technology Strategy Board and the Office for Low Emission Vehicles [4].

The Center for Sustainable Road Freight at the University of Cambridge recently investigated the level of $\mathrm{CO}_{2}$ abatement within a DF HGV. This study found that there is a 4, 9, and $12 \%$ reduction in $\mathrm{CO}_{2}$ emissions for DF urban, rural, and motorway HGVs, respectively [5]. However, when the global warming potential (GWP) of methane was included 
$\left(\mathrm{GWP}_{\mathrm{CH} 4}=34\right.$ on a 100 -year horizon [6]), there was an increase in $\mathrm{CO}_{2}$ equivalent $\left(\mathrm{CO}_{2} \mathrm{e}\right)$ emissions in the DF conversions due to unburned methane. These methane emissions led to a 17,13 , and $24 \%$ increase in $\mathrm{CO}_{2} \mathrm{e}$ emissions in DF urban, rural, and motorway driving cycles, respectively [7].

To evaluate whether these methane emissions can be addressed by methane oxidation catalysts (MOCs), this study seeks to determine the temperature-dependent oxidation efficiency of newly available MOCs from a number of manufacturers. An obstacle to this method is that methane oxidation requires exhaust temperatures higher than normal operating conditions of diesel-based after-treatment systems [8, 9], which was found to be an average of $400{ }^{\circ} \mathrm{C}$ over a drive cycle by Stettler et al. [5].

\subsection{Kinetic and Mass Transfer Mechanisms}

The properties of methane oxidation catalysts (monoliths, metallic oxide washcoats, and PGM particles) all influence the MOC conversion efficiency. Mass transfer and reaction kinetics control this oxidation process, which can be summarized as follows:

- Kinetic limitations - influenced by the condition of the active sites, temperature, and chemistry of the fluid and surface materials.

- Pore diffusion limitations - influenced by the washcoat thickness and pore size.

- Bulk diffusion limitations - influenced by the substrate channels, geometric surface area, and fluid turbulence [10].

As the reaction progresses from 0 to $100 \%$ oxidation with increased temperature, the rate limitations transition from reaction kinetics to mass transport. According to Heck et al., at approximately $20 \%$ conversion, the catalyst is at a sufficiently high temperature, such that transport processes are slower than the catalyst's intrinsic activity, which results in mass transfer limitations (pore and bulk diffusion) becoming dominant. As the gas temperature increases, the reactivity of the catalyst increases, which increases the temperature within the catalyst bed as a result of exothermic reactions. At higher temperatures where conversion efficiency is $>20 \%$ methane oxidation, rate limitations are related to mass transfer of reactants and their products through either pore diffusion or bulk mass transfer. Studies have shown that kinetic limitations can be improved by catalyst (PGM) selection while pore diffusion limitations can be reduced through larger pores within the washcoat [11].

\subsection{Approach}

Methane oxidation in dual-fuel exhaust streams is challenging because the conditions include low exhaust temperatures $\left(<400{ }^{\circ} \mathrm{C}\right)$, which reduce reactivity, and large amounts of water vapor, which chemisorb onto PGM reactive sites [8]. This study seeks to provide knowledge to overcome these obstacles by performing a full characterization study on six commercially available MOCs; determining the MOC conversion efficiency of each catalyst in controlled methane oxidation experiments with varying temperatures, flow rates, and stream compositions; and finding correlations between these characteristics and conversion efficiencies to determine favorable catalyst characteristics for methane oxidation. The six commercially available MOCs studied were procured from a number of catalyst manufacturers and distributers, representing a range of commercially available MOCs in use within the UK market.

\section{Methods}

\subsection{Characterization}

A limited amount of information was provided by the MOC manufacturers on catalyst composition and chemistry. The following techniques were used in catalyst characterization to determine the PGM loading (both Pd and Pt), particle size, catalytic surface area, Pd:Pt ratio, the washcoat surface area, pore volume, and pore size.

\subsubsection{PGM Particle Size-Transmission Electron Microscopy}

The catalyst washcoat including PGM nanoparticles was scraped off the monolith surface of each catalyst. This powder was then deposited on Agar Scientific carbon-film-coated transmission electron microscopy (TEM) grids for analysis. TEM images were obtained using an 80-200-kV TEM (Tecnai G2, FEI, USA), and particle sizes were determined through manual image analysis.

\subsubsection{Washcoat Morphology-Scanning Electron Microscopy}

Flat, rectangular catalyst pieces (approximately $5 \times 10 \times 2 \mathrm{~mm}$ ) were prepared from catalysts. Images were recorded on a FEI Verios 460 scanning electron microscopy (SEM) microscope with an acceleration voltage of $5 \mathrm{keV}$. SEM images were able to provide a visual, qualitative reference for the washcoat morphology of each sample.

\subsubsection{PGM Surface Composition-Energy-Dispersive Analyzer}

Following SEM imaging, energy-dispersive analyzer (EDX) spot analyses were obtained using an Oxford Instruments EDX detector to determine the elemental surface composition of the sample. An acceleration energy of $20 \mathrm{keV}$ was utilized. 


\subsubsection{PGM Surface Composition-X-ray Photoelectron Spectroscopy}

X-ray photoelectron spectroscopy (XPS) was used to characterize catalyst composition by irradiating the material surface layer with X-ray photons to form spectra from emitted electrons [12]. These spectra are used to identify the binding energy of different elements and compounds at surface sites. Flat, rectangular samples (approximately $5 \times 10 \times 2 \mathrm{~mm}$ ) were prepared from each catalyst for XPS analysis. The XPS spectra were taken with a Thermo Scientific ESCALAB 250Xi XPS microprobe. The system control, data gathering, and data processing were performed with the Thermo Scientific Avantage Data System.

\subsubsection{PGM Loading-Inductively Coupled Plasma-Optical Emission Spectroscopy}

As previous studies have demonstrated [9, 13], inductively coupled plasma-optical emission spectroscopy (ICP-OES) analysis allows for quantitative measurement of the metallic contents of the catalysts. In addition to Pd and Pt contents, the metals from the metallic oxides of the catalyst washcoat (Al, $\mathrm{Zr}$, and $\mathrm{Ce}$ ) were also determined. While typical sample preparation for ICP-OES requires samples to be dissolved in aqua regia $\left(2 \mathrm{~mL} 70 \%\right.$ concentrated $\mathrm{HNO}_{3}$ and $6 \mathrm{~mL} 36 \%$ concentrated $\mathrm{HCl}$ ), the ceramic substrates will not dissolve in such a solution. As a result, the samples had to be prepared in the following two different groups: ceramic substrates (samples 1, 4, 5, and 6) and metallic substrates (samples 2 and 3).

Initially, 1-2 $\mathrm{g}$ of all sample catalysts was dissolved in an $8 \mathrm{~mL}$ solution of aqua regia. The solution was made up to $25 \mathrm{~mL}$ with $18.2 \mathrm{~m} \Omega \mathrm{cm}$ ultrapure water after the removal of the ceramic substrate in batches $1,4,5$, and 6 . The ceramic substrate catalysts were made into a 1:10 solution, while the metallic-supported catalysts were formulated at 1:100 solutions because of the higher metallic concentration from the dissolved substrate. The standards used for calibration in the Optima 2100 DV Optical Emission Spectrometer for ICPOES analysis were prepared from Pd and Pt standards from Sigma-Aldrich. These $1000-\mathrm{mg} / \mathrm{L}$ concentration standards were diluted to $10 \mathrm{mg} / \mathrm{L}$ with $18.2 \mathrm{~m} \Omega \mathrm{cm}$ ultrapure water.

\subsubsection{Catalytic Surface Area}

The catalytic surface area was estimated as the amount of active sites available for reaction within the methane oxidation catalyst. The common technique employed to determine this value is $\mathrm{CO}$ chemisorption $[9,12]$. However, due to the toxicity of $\mathrm{CO}$, facilities were not available for chemisorption measurements during this study. Instead, particle size, PGM loading, and PGM density were used to give an indication of loading. This technique gives information for comparative purposes, but has a large error from the assumptions of correct TEM particle size estimations, $100 \%$ of the sphere surface area available for reactions, and that no PGM particles are beneath the washcoat.

\subsubsection{Washcoat Surface Area and Pore Size-Brunauer-Emmett-Teller $\mathrm{N}_{2}$ Absorption}

Samples were prepared to approximately $500-\mathrm{mm}^{3}$ bulk volume units $(4.4 \times 4.4 \times 25 \mathrm{~mm}$ for ceramic samples $)$. They were examined with a TriStar 3000 V6.08 Surface Area and Pore Size Analyzer. The surface area of each sample's washcoat was determined through the Brunauer-Emmett-Teller (BET) method. This process uses nitrogen adsorption and desorption isotherms to calculate the sample surface area $[9,12]$. Likewise, the washcoat pore volume and average pore size were determined from the nitrogen desorption behavior using the Barrett-Joyner-Halender (BJH) model. This model determines the pore volume (excluding the channel volumes) and pore size from the amount of nitrogen desorbed from the washcoat as the relative pressure is decreased incrementally over time [14].

In the BET and BJH washcoat surface analyses, small samples were cut out from larger methane oxidation catalysts. Care was taken to minimize washcoat loss but exposed ceramic occurred. A bare piece of ceramic was passed through the same analyses, where surface area, pore volume, and pore size estimates were obtained. As expected, there was a lower surface area, smaller pore volume, and larger pore size associated with this sample. Using these values and the estimated amount of exposed ceramic, it was determined that there is a $10 \%$ error within the presented washcoat surface area and pore size data.

\subsection{MOC Conversion Efficiency Testing}

The MOC oxidation efficiency was determined against varying temperatures, flow rates, and stream compositions (air, $\mathrm{CO}, \mathrm{H}_{2} \mathrm{O}, \mathrm{CO}_{2}$, etc.). This was conducted by reacting a premixed stream containing methane within a tube furnace. The methane concentration of $5000 \mathrm{ppm}$ was representative of DF HGV emissions. Two different stream experimental groups were made. One group of samples had their methane conversion efficiency tested with a stream consisting of air and methane, which will be referred to as the "air-methane" experiments henceforth. The second group of experiments was performed using a stream consisting of engine exhaust from a diesel engine, where methane was added to the stream before a 10-m-long, $191^{\circ} \mathrm{C}$ heated line that led to the furnace (Fig. 1).

The engine exhaust sample was taken after the turbocharger and before the engine's diesel oxidation catalyst (DOC), while the engine was controlled by an $\mathrm{AC}$ dynamometer running at a speed of $1500 \mathrm{rpm}$ and a load of $75 \mathrm{Nm}$. The exhaust 
Fig. 1 Exhaust-methane experimental setup

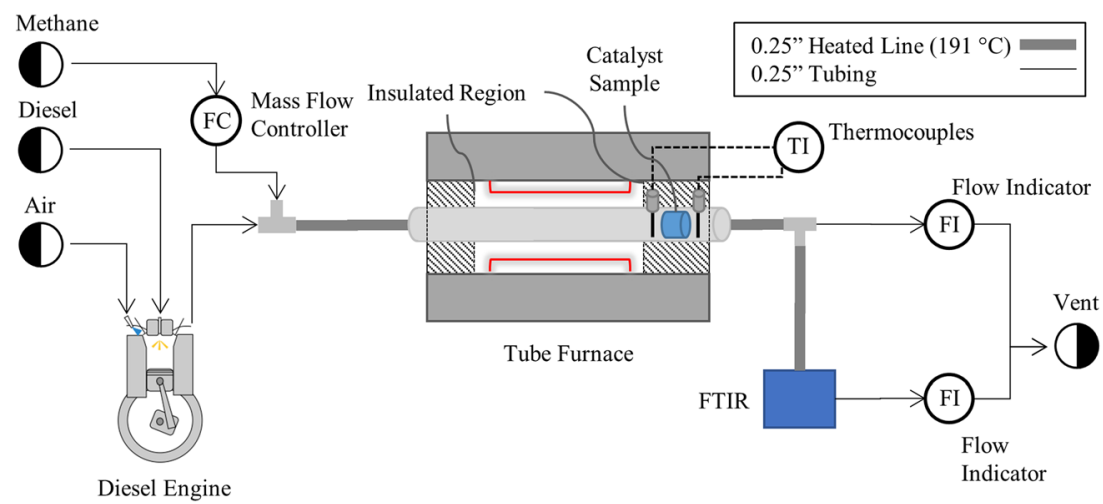

gas recirculation (EGR) valve was closed, but the engine was operating at its normal control strategy otherwise. The backpressure at the sampling point is normally 1.05 barA but was increased to approximately 1.5 barA with a butterfly valve mounted downstream to extract higher exhaust sample flow rates. Other engine specifications can be seen in Table 1 . These experiments will be referred to as "exhaust-methane" experiments henceforth. The diesel fuel complied to EN standard, EN 590 (2009), which has a maximum sulfur level of $10 \mathrm{ppm}$. At the given test conditions, the estimated sulfur concentration in the exhaust was less than $200 \mathrm{ppb}$, which is not expected to affect catalytic performance over the course of exposure (typically $<1 \mathrm{~h}$ ). This experimental setup is a modification of the Herreros et al. [15] study that added hydrogen to the exhaust stream after a diesel engine before testing oxidation levels in a tube furnace.

The furnace used in this experiment is an Elite TSH17 model with a $0.45-\mathrm{m}$ heated zone. The samples were heated from 100 to $600^{\circ} \mathrm{C}$ at a rate of $10^{\circ} \mathrm{C} / \mathrm{min}$. Temperatures were controlled by a Eurotherm 2416 temperature controller. The catalysts samples were placed in an insulated region near the end of the furnace. This gave the pre-catalyst stream the full length of the furnace-heating region to reach the desired temperature and reduced the effect of undesired radial heating.

To record the temperature of the exhaust stream both before and after the catalyst, the catalyst sample was placed between

Table 1 Diesel engine specifications

\begin{tabular}{ll} 
Engine specification & \\
\hline Class & Light-duty diesel (DW10C) \\
Manufacturer & PSA (Peugeot/Citroën), finished by Ford \\
Emission standard & EURO V \\
Number of cylinders & 4 \\
Valves per cylinder & 4 \\
Rated power $(\mathrm{kW})$ & 101 \\
Peak torque $(\mathrm{Nm})$ & $330 \mathrm{Nm}$ \\
Injection & 1 pilot injection, 1 main injection \\
\hline
\end{tabular}

two thermocouples, spaced approximately $125 \mathrm{~mm}$ from each other. The MOC conversion efficiency (percent methane oxidation versus temperature) of each catalyst was determined against the pre-catalyst gas temperature.

The methane stream was fed into the system with the use of mass flow controllers. A 1-2-L/min stream was diverted from the effluent gas and analyzed with a MKS Multigas FTIR gas analyzer, which detected gas concentrations of $\mathrm{CH}_{4}, \mathrm{H}_{2} \mathrm{O}$, $\mathrm{CO}_{2}, \mathrm{CO}$, and $\mathrm{NO}_{\mathrm{x}}$ among others. In an experimental run with the FTIR analyzer over a 15-min interval bypassing the catalyst sample, the following concentrations (with ranges) were measured: $\mathrm{H}_{2} \mathrm{O} 4.89 \%$ (4.60-5.98 \%), $\mathrm{CO}_{2} 5.97 \%$ (5.86$6.07 \%)$, CO 143 ppm (140-146 ppm), NO 349 ppm (343$354 \mathrm{ppm}$ ), and $\mathrm{NO}_{2} 36.1 \mathrm{ppm}$ (12.3-60.4 ppm). Both system flow rates were monitored with rotameters after the tube furnace and the FTIR analyzer, where they were passed through water traps before final venting.

\subsection{Characteristic-Conversion Efficiency Correlations}

The following eight catalyst characteristics were used to determine correlations with catalyst efficiency: PGM loading, Pd loading, Pt loading, particle size, catalytic surface area, Pd:Pt ratios, surface area, pore volume, and pore size. These were plotted against the $50 \%$ methane oxidation temperature $\left(T_{50} \%\right)$ for both air-methane and exhaust-methane experiments at $30,000 \mathrm{~h}^{-1}$ gas hourly space velocities (GHSVs). Supporting information from the GHSV comparison and concentration comparison experiments were used to strengthen conclusions and for additional insight.

\subsection{Activation Energies}

The kinetically limited region of the MOC test was quantified by determining the activation energies of each catalyst at different operating conditions. Given that the concentration of oxygen is much greater than the concentration of methane and is approximately constant, we assume that methane 
oxidation is a pseudo-first-order reaction with respect to methane, and the reaction rate is represented by

$r=k C$,

where $r, k$, and $C$ are the reaction rate $\left(\mathrm{mol} / \mathrm{s} \mathrm{m}^{3}\right)$, the reaction rate constant $(1 / \mathrm{s})$, and methane concentration $\left(\mathrm{mol} / \mathrm{m}^{3}\right)$, respectively. The rate constant (Eq. 2) relates the reaction rate to the activation energy and the temperature,

$k=k_{o} e^{\left(-E_{a} / R T\right)}$,

where $E_{a}, R$, and $T$ are the activation energy $(\mathrm{kJ} / \mathrm{mol})$, universal gas constant $(\mathrm{kJ} / \mathrm{mol} \mathrm{K})$, and temperature $(\mathrm{K})$, respectively. To solve for the activation energy, a methane stream flowing through a catalyst monolith can be represented by the onedimensional material balance of a plug flow reactor operating at isothermal, steady state conditions [16] (Eq. 3),

$v\left(\frac{d C}{d x}\right)=-r$

where $v$ and $x$ are the gas velocity $(\mathrm{m} / \mathrm{s})$ and length $(\mathrm{m})$, respectively. After combining Eqs. 1 and 3, the material balance equation can be solved for the inlet $\left(C_{i}\right)$ and outlet $\left(C_{o}\right)$ concentrations of methane along the length of the catalyst sample

$\int_{C_{i}}^{C_{o}} \frac{1}{C} d C=\int_{0}^{L} \frac{-k}{v} d x$.

Solving Eq. 4 results in a relation for the inlet and outlet concentrations of methane,

$\ln \left(\frac{C_{o}}{C_{i}}\right)=-\frac{L}{v} k=-\frac{1}{\mathrm{GHSV}} k_{o} e^{\left(-E_{a} / \mathrm{RT}\right)}$

where $L$ and GHSV are the catalyst length (m) and gas hourly space velocity $(1 / \mathrm{h})$, respectively. A linear relation is found for activation energy, which allows for fitting of experimental data,

$\ln \left[\ln \left(\frac{C_{o}}{C_{i}}\right)\right]=\ln \left(\frac{k_{0}}{\mathrm{GHSV}}\right)-\left(\frac{1}{\mathrm{RT}}\right)\left(E_{a}\right)$.

\section{Results and Discussion}

\subsection{Characterization}

A summary of the characteristics of the different catalyst samples is shown in Table 2. The results of the MOC catalyst characterization are discussed in detail in the following sections.

\subsubsection{PGM Particle Size-TEM}

Figure 2 shows the PGM particles of the fresh MOC samples. Approximate PGM particle size ranges were determined (Table 2), where sample 1 has the smallest particles (2$3 \mathrm{~nm}$ ), samples 2 and 3 have medium-size particles (4$10 \mathrm{~nm})$, and samples $4-6$ have the largest particle sizes (8$10 \mathrm{~nm})$.

\subsubsection{Washcoat and PGM Surface Composition-EDX and XPS}

The washcoat composition and surface PGM loading was determined through both EDX and XPS [17]. These analyses indicated that every sample contained palladium with an alumina washcoat, samples 1 and 4-6 contain platinum, samples 2 and 4-6 contain zirconia in the washcoat, and sample 2 contains ceria in the washcoat.

\subsubsection{PGM Loading-ICP-OES}

PGM content and washcoat composition were quantified by ICP-OES analysis. The total PGM loading results (Table 2) show that sample 1 had the highest PGM content $\left(340 \mathrm{~g} / \mathrm{ft}^{3}\right.$, $\left.12,000 \mathrm{~g} / \mathrm{m}^{3}\right)$, followed by samples 4-6 (120-160 g/ $\mathrm{ft}^{3}, 4300$ $5700 \mathrm{~g} / \mathrm{m}^{3}$ ). Samples 2 and 3 had the lowest PGM loadings of 6 and $40 \mathrm{~g} / \mathrm{ft}^{3}$ (210 and $\left.1400 \mathrm{~g} / \mathrm{m}^{3}\right)$, respectively. The highest percent error in spectroscopy recordings from the ICP-OES equipment was $1.6 \%$. Preparation error was minimized through initial trial experiments to ensure a robust process, where the error in reported results was minimized to an average of 8.9 and $10.9 \%$ for $\mathrm{Pd}$ and Pt loading recordings, respectively.

\subsubsection{Catalytic Surface Area}

The catalytic surface areas for each MOC were estimated using the average particle sizes from TEM measurements, PGM loading values from ICP-OES measurements, and densities of $\mathrm{Pd}\left(12 \mathrm{~g} / \mathrm{cm}^{3}\right)$ and $\mathrm{Pt}\left(22 \mathrm{~g} / \mathrm{cm}^{3}\right)$ [18]. These estimated catalytic surface areas are illustrative but uncertain due to the low accuracy of TEM particle size estimations and assumption of spherical particles to represent available surface. Estimated surface areas in Table 2 indicate that sample 1 has the largest catalytic surface area $\left(6200 \mathrm{~cm}^{2} / \mathrm{cm}^{3}\right)$ because of low particle sizes and high PGM loading values. Samples 4-6 had roughly 20-25\% (1200-1500 $\left.\mathrm{cm}^{2} / \mathrm{cm}^{3}\right)$ of the estimated catalytic surface area of sample 1 , while samples $2-3\left(70-710 \mathrm{~cm}^{2} / \mathrm{mL}\right)$ had an order of magnitude less. Considering that the error (estimated at $50 \%$ ) is approximately the same for all samples, the results allow for ranking of sample surface areas among catalyst studied. 
Table 2 MOC characterization summary data

Fig. 2 TEM images of PGM particles on fresh MOC samples

\begin{tabular}{|c|c|c|c|c|c|c|}
\hline & Sample 1 & Sample 2 & Sample 3 & Sample 4 & Sample 5 & Sample 6 \\
\hline \multirow[t]{2}{*}{$\operatorname{PGM}\left(\mathrm{g} / \mathrm{ft}^{3} ; g / m^{3}\right)^{\mathrm{a}}$} & 340 & 6 & 40 & 130 & 120 & 160 \\
\hline & 12,000 & 210 & 1,400 & 4,400 & 4,300 & 5,700 \\
\hline \multirow[t]{2}{*}{$\operatorname{Pd}\left(\mathrm{g} / \mathrm{ft}^{3} ; g / m^{3}\right)^{\mathrm{a}}$} & 290 & 6 & 40 & 120 & 110 & 130 \\
\hline & 10,000 & 210 & 1,400 & 4,100 & 4,000 & 4,700 \\
\hline \multirow[t]{2}{*}{$\operatorname{Pt}\left(\mathrm{g} / \mathrm{ft}^{3} ; g / m^{3}\right)^{\mathrm{a}}$} & 50 & 0 & 0 & 10 & 10 & 30 \\
\hline & 2,000 & 0 & 0 & 300 & 300 & 1,000 \\
\hline $\mathrm{Pd} / \mathrm{Pt}$ ratios $^{\mathrm{a}}$ & 6 & NA & NA & 16 & 11 & 5 \\
\hline Particle size $(\mathrm{nm})^{\mathrm{b}}$ & $3-4$ & $6-10$ & $4-6$ & $8-10$ & $8-10$ & $8-10$ \\
\hline Catalytic surface area & 1,700 & 200 & 2,000 & 3,400 & 3,300 & 4,200 \\
\hline$\left(\mathrm{m}^{2} / \mathrm{ft}^{3} ; \mathrm{cm}^{2} / \mathrm{cm}^{3}\right)^{\mathrm{c}}$ & 6,200 & 70 & 710 & 1,200 & 1,170 & 1,500 \\
\hline Washcoat surface area & 7 & 2 & 2 & 6 & 5 & 5 \\
\hline$\left(\mathrm{m}^{2} / \mathrm{ft}^{3} ; \mathrm{m}^{2} / \mathrm{cm}^{3}\right)^{\mathrm{d}}$ & 20 & 7 & 6 & 16 & 13 & 14 \\
\hline Washcoat pore volume & 2 & 1 & 1 & 2 & 2 & 2 \\
\hline$\left(\mathrm{cm}^{3} / \mathrm{ft}^{3} ; \mathrm{mm}^{3} / \mathrm{cm}^{3}\right)^{\mathrm{e}}$ & 74 & 29 & 20 & 68 & 67 & 53 \\
\hline Washcoat pore size $(\mathrm{nm})^{\mathrm{e}}$ & 10 & 12 & 8 & 13 & 15 & 11 \\
\hline
\end{tabular}

${ }^{\mathrm{a}} \mathrm{ICP}-\mathrm{OES}$

${ }^{\mathrm{b}} \mathrm{TEM}$

${ }^{\mathrm{c}}$ Calculated from loading, particle size, and density values

${ }^{\mathrm{d}}$ BET method

${ }^{\mathrm{e}} \mathrm{BJH}$ desorption isotherm
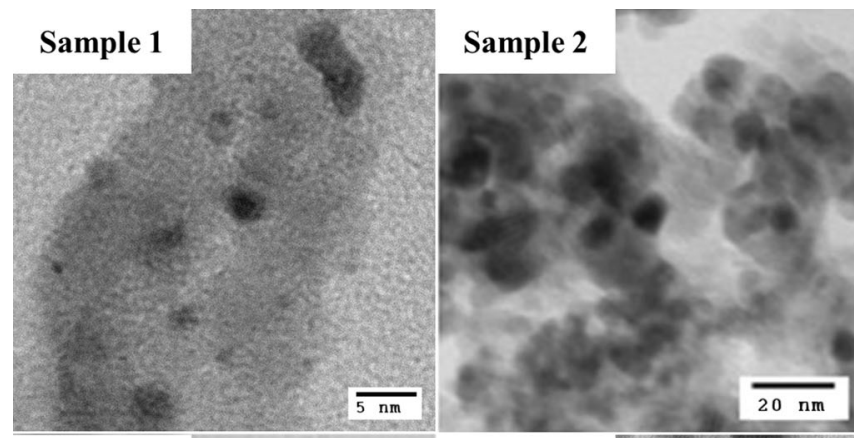

Sample 3
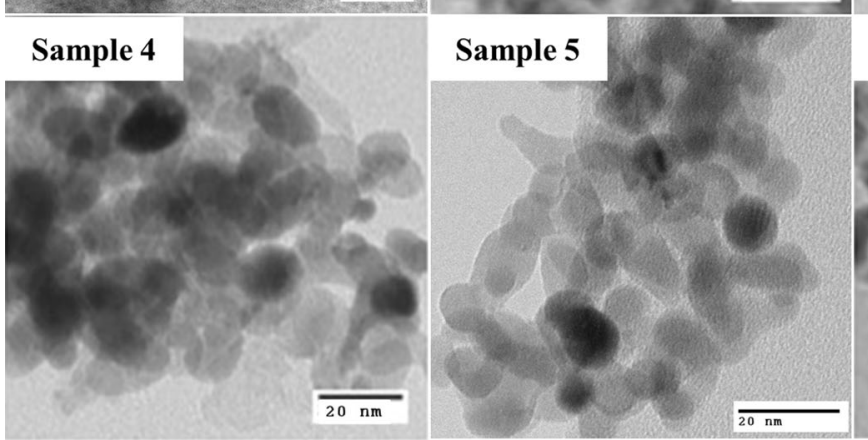
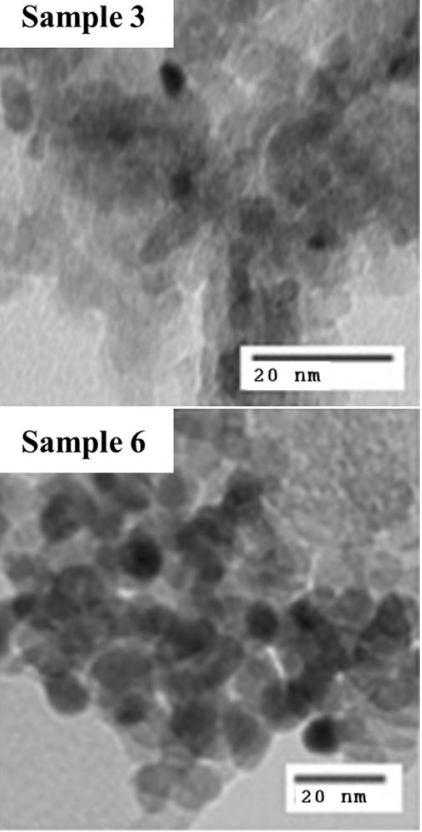


\subsubsection{Washcoat Surface Area and Pore Size-BET N $N_{2}$ Physisorption}

In addition to varying composition, catalyst washcoats had different surface areas and porosities. The disparity between ceramic and metallic substrates values, which have different densities, was eliminated by normalizing the measured massspecific surface areas by the bulk densities of each sample (including void channel spaces). The BET analysis showed that sample 1 had the highest washcoat surface area $\left(20 \mathrm{~m}^{2} / \mathrm{cm}^{3}\right)$, followed by samples $4-6\left(13-16 \mathrm{~m}^{2} / \mathrm{cm}^{3}\right)$ and samples $2-3$ $\left(6-7 \mathrm{~m}^{2} / \mathrm{cm}^{3}\right)$. Similar trends were observed for porosity results from the $\mathrm{BJH}$ desorption isotherm. Unlike the surface area and pore volume measurements, there was a small range of values for pore size between 8 to $15 \mathrm{~nm}$ (Table 2).

These three measurements play a significant role in each control regime present in these methane oxidation catalysts. The washcoat surface area affects the kinetically limited region, as it determines the area of support of PGM nanoparticles. The diffusion limited regions are controlled by the pore volume and size, as these variables can have large effects on the rate of mass transfer within the catalyst.

\subsection{MOC Conversion Efficiency Evaluation}

Figure 3 shows the methane oxidation efficiency curves of the six MOC samples at $30,000 \mathrm{~h}^{-1}$ GHSV, plotted as methane oxidation percentage against the pre-catalyst oxidation temperature.

Sample 1 has the lowest methane oxidation temperatures $\left(T_{50} \% 304^{\circ} \mathrm{C}\right)$, which correspond to the high PGM loading and washcoat surface area. Samples 5 and 6 had slightly higher $T_{50} \%$ values of 312 and $333{ }^{\circ} \mathrm{C}$, respectively, which are in line with the PGM loadings (Table 2). Sample 3 performed well $\left(T_{50} \%\right.$ value of $\left.361{ }^{\circ} \mathrm{C}\right)$, despite the low PGM loading and low washcoat surface area. It is hypothesized that there is more uniform heating throughout the metallic substrate used for this catalyst, which could result in lower-

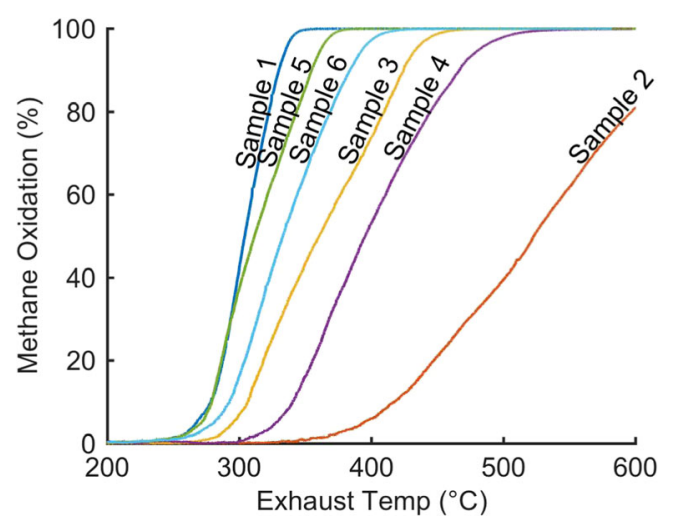

Fig. 3 Methane oxidation versus temperature within an air-methane supply at $30,000 \mathrm{~h}^{-1} \mathrm{GHSV}$

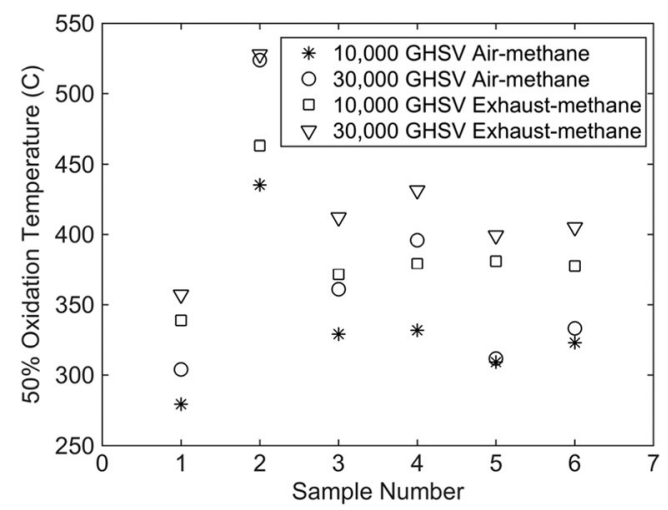

Fig. 4 Fifty-percent oxidation temperature $\left(T_{50} \%\right)$ at 10,000 and 30,000 GHSV for air-methane and exhaust-methane test gas

temperature peaks in the catalyst and a spread of highconversion efficiencies throughout its full length. Despite the higher PGM loading, sample 4 had a higher $T_{50} \%\left(396^{\circ} \mathrm{C}\right)$ value than sample 3 . Sample 2 had the most delayed oxidation $\left(T_{50} \%=524{ }^{\circ} \mathrm{C}\right)$, which is likely a result of the low PGM loadings $\left(6 \mathrm{~g} / \mathrm{ft}^{3}\right)$. Full oxidation was achieved before $400{ }^{\circ} \mathrm{C}$ for samples 1 and 5 in the $30,000 \mathrm{~h}^{-1}$ GHSV airmethane experiments, which is a promising result for the use of these catalysts in DF HGVs.

Figure 4 shows how the $T_{50} \%$ values decrease with an increase in GHSVs and the change in operating conditions from air-methane to exhaust-methane. There are delayed $T_{50} \%$ values for exhaust-methane experiments because of the presence of water. Water partially deactivates the Pd particles and its oxide (PdO), which is considered to be the active component in methane oxidation [19, 20]. On average, the difference in $T_{90} \%$ values between the air-methane and exhaustmethane $30,000 \mathrm{~h}^{-1}$ GHSV values for all samples is $45^{\circ} \mathrm{C}$. $T_{50} \%$ values increase with increasing GHSVs because the methane residence time is reduced within the catalyst. Only sample 1 was able to display complete methane oxidation by approximately $400{ }^{\circ} \mathrm{C}$ in these DF HGV exhaust conditions.

It was assumed that a negligible amount of catalyst aging had occurred because of the low levels of water and chemical

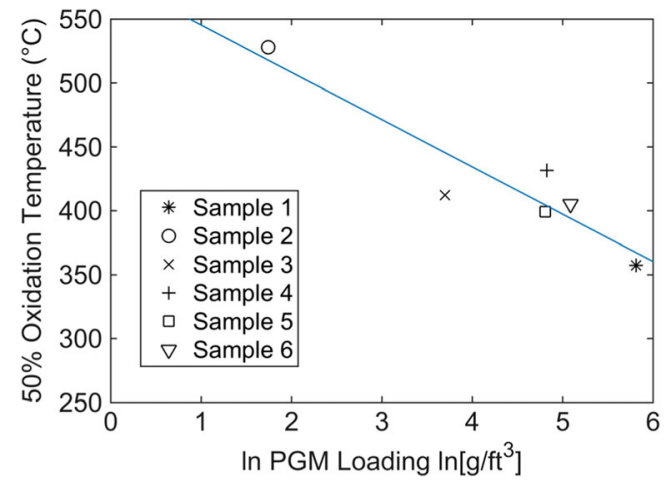

Fig. 5 Exhaust-methane $30,000 \mathrm{~h}^{-1}$ GHSV-natural log PGM loading correlations 

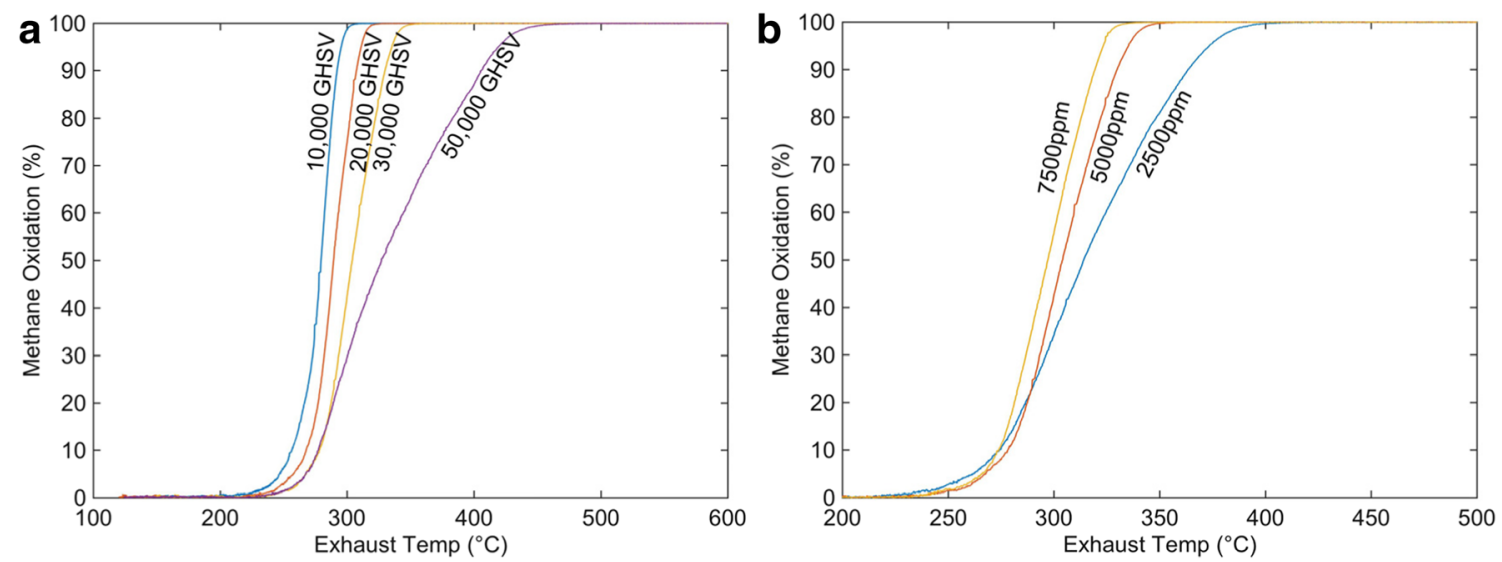

Fig. 6 Sample 1 methane oxidation for varying GHSV (a, left) and methane concentration (b, right)

poisoning. This assumption coupled with a low amount of catalyst core samples for samples $2-5$ resulted in the re-use of these catalysts core samples for several experiments. Controlled thermal aging experiments were performed, which resulted in a $5.2 \%$ increase in $T_{50} \%$ values over five iterations. Therefore, a negligible error $(<10 \%)$ was associated with the repeated $T_{50} \%$ measurements.

\subsection{Correlations}

Correlations were made for each catalyst sample with both characteristic and conversion efficiency data. Considering that the MOC conversion efficiency in each sample was similar but slightly delayed between the 10,000- and $30,000-\mathrm{h}^{-1}$ GHSV flow rates, the following discussion only pertains to $T_{50} \%$ values at $30,000 \mathrm{~h}^{-1}$ GHSVs in exhaust-methane experiments. The following conclusions are a result of observed trends within the six catalyst samples, which have a small statistical significance because of the small sample size.

PGM loadings had a large range of $340 \mathrm{~g} / \mathrm{ft}^{3}\left(12,000 \mathrm{~g} / \mathrm{m}^{3}\right)$ to $6 \mathrm{~g} / \mathrm{ft}^{3}\left(210 \mathrm{~g} / \mathrm{m}^{3}\right)$ in samples 1 to 2 , respectively. The data show an exponential decrease in $T_{50} \%$ values with increasing PGM loading. Figure 5 shows this trend, with $T_{50} \%$ values plotted against the natural logarithm of PGM loading $\left(R^{2}=0.86\right)$. The exponential decay in $T_{50} \%$ values with increasing PGM loading indicates that diminishing gains occur for high loadings and other strategies must be employed to improve MOC conversion efficiencies. Similar results were observed for Pd $\left(R^{2}=0.87\right)$ and $\mathrm{Pt}\left(R^{2}=0.70\right)$ loading but are highly cross correlated with total PGM loading, prohibiting conclusions about the impact of $\mathrm{Pd}$ and Pt loading separately on $T_{50} \%$. Other characteristics (with $R^{2}$ values) that possibly effect $T_{50} \%$ values are the decrease of Pd:Pt ratios $(0.47)$, increase in washcoat surface areas $(0.46)$, and increased in pore volumes $(0.34)$. No noticeable effects were found with changing PGM particle size $(0.18)$ or washcoat pore size $(0.12)$.

\subsection{GHSV Comparison}

Additional studies were performed to investigate methane oxidation efficiency with varying GHSVs and methane concentrations. The GHSV is dependent on both the flow rate of the methane-containing stream and the bulk volume of the catalyst. As expected, MOC conversion efficiency increases with a decrease in GHSV or an increase in methane residence time. This effect is more pronounced after $20 \%$ oxidation or as the reaction is leaving the kinetically limited region and entering the mass transfer-controlled region (Fig. 6a). The $T_{10} \%$ values in the kinetically limited region have a small initial increase with increasing GHSVs but eventually, plateau for the larger GHSVs. The $T_{90} \%$ values in the diffusion-limited region have an exponential increase with increasing GHSVs. A temperature increase is needed to increase the reaction rate and provide full methane oxidation. Therefore, higher temperatures are required to reach full methane oxidation in high GHSV conditions. GHSVs can be lowered and MOC conversion efficiencies improved by increasing the oxidation catalyst bulk volume (increased diameter and length).
Table 3 Mean activation energies and pre-exponential factors for varying operating conditions and methane concentrations

\begin{tabular}{lll}
\hline & Activation energy, kJ/mol (SD) & $k_{o}, \mathrm{~h}^{-1}(\mathrm{SD})$ \\
\hline Operating condition & & \\
Air-methane $30,000 \mathrm{~h}^{-1} \mathrm{GHSV}$ & $50.1(8.1)$ & $8.2 \times 10^{9}\left(1.3 \times 10^{10}\right)$ \\
Exhaust-methane $30,000 \mathrm{~h}^{-1} \mathrm{GHSV}$ & $54.9(13.1)$ & $1.7 \times 10^{9}\left(3.6 \times 10^{9}\right)$ \\
\hline
\end{tabular}




\subsection{Concentration Comparison}

Methane concentration comparisons were made for sample 1 in air-methane stream conditions. Methane concentrations of 2500, 5000, and $7500 \mathrm{ppm}$ were used, and their respective MOC conversion efficiencies in air-methane experiments can be viewed in Fig. 6b. An increase in conversion efficiencies was observed with an increase in methane concentration.

Figure $6 \mathrm{~b}$ shows the approximately equivalent $T_{10} \%$ values for the initial methane oxidation within the kinetically limited region. However, the methane oxidation profiles begin to separate as temperatures increase. Methane oxidation is an exothermic reaction, which results in an increased temperature within the catalyst. These increased temperatures, associated with more exothermic methane oxidation reactions in higher concentrations, result in faster kinetics and higher rates of mass transfer within the catalyst. These results suggest that with increasing methane concentrations, $T_{50} \%$ oxidation temperatures decrease linearly, while in the mass transfer region $\left(T_{90} \%\right)$, methane oxidation temperatures decrease exponentially.

Manufacturers have suggested the injection of hydrocarbons prior to the catalyst to increase MOC oxidation efficiency. The results shown in Fig. 6b indicate that higher hydrocarbon concentration does increase MOC oxidation efficiency. Hydrocarbons with high propensity to combust, such as diesel, could be used to ensure that the injected hydrocarbons oxidize within the catalyst.

\subsection{Activation Energies}

The mean activation energies $\left(E_{a}\right)$ and pre-exponential factors $\left(k_{0}\right)$ of the six samples were calculated utilizing Eq. 6 and the experimental data, shown in Table 3. $E_{a}$ values were found to be comparable across samples and conditions, whereas the pre-exponential factor $\left(k_{0}\right)$ varied but were highly uncertain. The isothermal assumption upon which Eq. 6 relied upon was not valid for lower flow rates through the catalyst, where

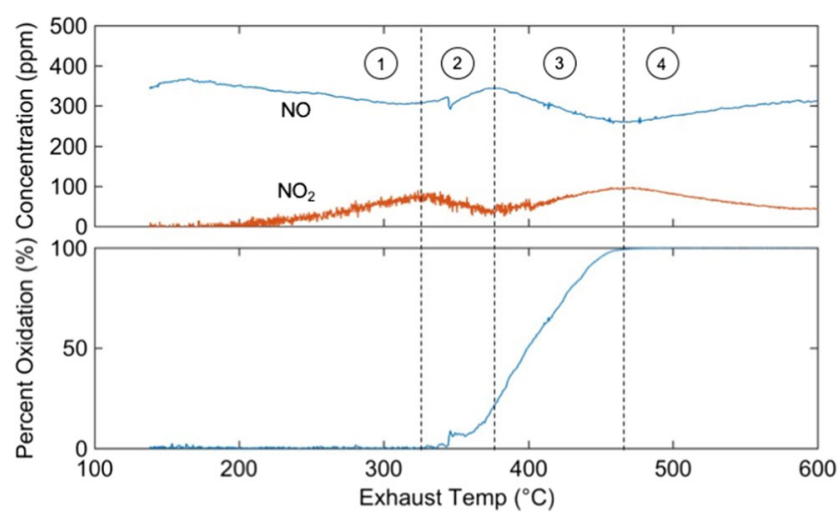

Fig. 7 Sample 5 exhaust-methane $\mathrm{NO}$ and $\mathrm{NO}_{2}$ concentrations with varying temperatures
$10,000 \mathrm{~h}^{-1} \mathrm{GHSV}$ had greater than $100^{\circ} \mathrm{C}$ difference between catalyst faces. Higher flow rates, $30,000 \mathrm{~h}^{-1} \mathrm{GHSV}$, had lower differential temperatures $\left(\Delta T<40^{\circ} \mathrm{C}\right)$ and are comparable $\left(\Delta T<5{ }^{\circ} \mathrm{C}\right)$ for the portion of the experiment where the activation energies were determined. While Fig. 4 indicates that the $T_{50} \%$ was higher for methane oxidation in exhaust, the activation energies were not found to be statistically different within the two systems.

\subsection{Effect on $\mathrm{NO}_{\mathrm{x}}$}

An interesting behavior was observed with the $\mathrm{NO}_{\mathrm{x}}$ concentrations of the engine exhaust experiments (Fig. 7). While total $\mathrm{NO}_{\mathrm{x}}$ concentrations remain relatively constant throughout the experiment, the relative concentrations of $\mathrm{NO}$ and $\mathrm{NO}_{2}$ change with varying MOC temperature. Compared against its associated MOC oxidation profile (Fig. 7), four regions of $\mathrm{NO}_{\mathrm{x}}$ behavior can be observed.

The trends in $\mathrm{NO} / \mathrm{NO}_{2}$ ratios for the various regions are governed by

1. As the temperatures increases, NO begins to oxidize within the MOC before methane oxidation begins.

2. This region coincides with the kinetically limited region of catalytic methane oxidation. Literature suggests that there are many competitive reactions within the catalyst [15, 21], which would reduce the rate of $\mathrm{NO}$ oxidation at the early stages of $\mathrm{CH}_{4}$ oxidation. Additionally, according to Lefort et al. [21], hydrocarbons can completely or partially reduce $\mathrm{NO}_{2}$ because of the assistance of $\mathrm{NO}_{2}$ in the early stages of hydrocarbon oxidation. The couplings of these two activities results in a net increase of $\mathrm{NO}$ and decrease for $\mathrm{NO}_{2}$.

3. As the temperature increases and the reaction passes outside of the kinetically limited region, there are more pathways for methane oxidation, such as platinum or the metallic oxide washcoats, which provide more active sites for other gases to react. Therefore, there is no longer a competitive reaction within this diffusion limited region, and $\mathrm{NO}$ begins oxidizing into $\mathrm{NO}_{2}$ again.

4. The last region begins after full oxidation has been reached and is characterized by the reduction of $\mathrm{NO}_{2}$ into $\mathrm{NO}$ in accordance with the thermodynamic properties of their equilibrium reaction [22].

\section{Conclusions}

This work shows that the near-complete methane oxidation can be achieved at the $400{ }^{\circ} \mathrm{C}$ average exhaust temperatures in DF HGV vehicles with current commercially available methane oxidation catalysts at GHSVs of $30,000 \mathrm{~h}^{-1}$. However, more improvements in MOCs are needed for lean- 
burn combustion systems with low exhaust temperatures, such as dual fuel in compression ignition engines and lean burn SI CNG. Of the six commercially available MOCs tested, sample 1 was able to achieve the desired $100 \%$ oxidation at approximately $400{ }^{\circ} \mathrm{C}$ in DF HGV exhaust conditions and at a GHSV of $30,000 \mathrm{~h}^{-1}$. However, this high MOC conversion efficiency has an associated high cost, as sample 1 had a high PGM content. Less loaded catalysts were able to achieve full oxidation at approximately $450{ }^{\circ} \mathrm{C}$.

Methane oxidation catalysts can achieve low $T_{50} \%$ $\left(<350{ }^{\circ} \mathrm{C}\right)$ when properties are in line with sample 1 , which had a $340 \mathrm{~g} / \mathrm{ft}^{3}\left(12,000 \mathrm{~g} / \mathrm{m}^{3}\right)$ PGM loading, a 6:1 Pd:Pt ratio, and a high alumina washcoat with a $20 \mathrm{~m}^{2} / \mathrm{cm}^{3}$ washcoat surface area and a $74 \mathrm{~mm}^{3} / \mathrm{cm}^{3}$ washcoat pore volume. The high PGM loading of sample 1 and subsequent high cost may be reduced by using metallic substrates, which allow for more homogenous temperature distributions throughout the MOC, such as sample 3. While additional MOC chemistries may improve performance and lower costs, the results from this study indicate that after-treatment of DF engine exhaust could achieve significant reductions in $\mathrm{CH}_{4}$ emissions, but MOCs must be appropriately sized and have correct catalyst formulations. These results indicate that while MOCs do exist that can achieve meaningful methane emission reductions, a number of commercially available MOCs do not meet the requirements for low-temperature $\left(<400{ }^{\circ} \mathrm{C}\right)$ oxidation. All catalysts had higher $T_{50} \%$ temperatures using diesel exhaust which contained water and which reduced catalyst activity. Suggested strategies of MOC improvement may achieve increased methane conversion efficiency by locally increasing the catalyst surface temperature by injecting volatile hydrocarbons (e.g., diesel fuel) into the exhaust upstream of the MOC. Such strategies should be employed carefully, so as not to increase the absolute magnitude of unburned hydrocarbons exhausted, even while conversion efficiency of methane may be improved, and also consider the overall energy consumption and $\mathrm{CO}_{2} \mathrm{e}$ emissions.

Acknowledgments We acknowledge support from the UK Engineering and Physical Sciences Research Council (EP/K00915X/1), the UK Department for Transport, the Office for Low Emission Vehicles and Innovate UK (project reference 400266), and the industrial partners of the Centre for Sustainable Road Freight. GreenUrban Technologies Ltd. (3) and Prins Autogas UK Ltd. (1) provided the samples for testing in this study.

Open Access This article is distributed under the terms of the Creative Commons Attribution 4.0 International License (http:// creativecommons.org/licenses/by/4.0/), which permits unrestricted use, distribution, and reproduction in any medium, provided you give appropriate credit to the original author(s) and the source, provide a link to the Creative Commons license, and indicate if changes were made.

\section{References}

1. Department of Energy \& Climate Change (DECC). Official statistics: final UK greenhouse gas emissions (2014)

2. European Commission. Climate action-reducing $\mathrm{CO}_{2}$ emissions from heavy-duty vehicles (2015)

3. U.S. Energy Information Administration. Environment - carbon dioxide emission factors for stationary combustion (2011)

4. A.\& Cenex. Low carbon truck and refuelling infrastructure demonstration trial evaluation. First annual report to the DfT executive summary for publication (2014)

5. Stettler, M., Midgley, W., Swanson, J., Cebon, D., Boies, A.M.: Greenhouse gas and noxious emissions from dual fuel diesel and natural gas heavy goods vehicles. Environ. Sci. Technol. 50, 2018 2026 (2016). doi:10.1021/acs.est.5b04240

6. Myhre, G., Shindell, D., Bréon, F.-M., Collins, W., Fuglestvedt, J., Huang, J., et al.: Anthropogenic and natural radiative forcing. In: Climate Change 2013: The physical science basis. contribution of working group I to the fifth assessment report of the intergovernmental panel on climate change (2013)

7. Stettler, M., Midgley, W., Cebon, D., Boies, A.: Greenhouse gas emissions from dual fuel HGVs - Project 4D interim report (2014)

8. Gélin, P., Urfels, L., Primet, M., Tena, E.: Complete oxidation of methane at low temperature over Pt and Pd catalysts for the abatement of lean-burn natural gas fuelled vehicles emissions: influence of water and sulphur containing compounds. Catal. Today $\mathbf{8 3}, 45$ 57 (2003). doi:10.1016/S0920-5861(03)00215-3

9. Matam, S.K., Otal, E.H., Aguirre, M.H., Winkler, A., Ulrich, A., Rentsch, D., et al.: Thermal and chemical aging of model three-way catalyst $\mathrm{Pd} / \mathrm{Al}_{2} \mathrm{O}_{3}$ and its impact on the conversion of $\mathrm{CNG}$ vehicle exhaust. Catal. Today 184, 237-244 (2012). doi:10.1016/j. cattod.2011.09.030

10. Heck, R.M., Farrauto, R.J., Gulati, S.T.: Catalytic air pollution control: commercial technology; Chapter 1-Catalyst Fundamentals. John Wiley \& Sons, New Jersey (2009)

11. Heck, R.M., Farrauto, R.J., Gulati, S.T.: Catalytic air pollution control: commercial technology; Chapter 4-Monolithic Reactors for Environmental Catalysis. John Wiley \& Sons, New Jersey (2009)

12. Heck, R.M., Farrauto, R.J., Gulati, S.T.: Catalytic air pollution control: commercial technology; Chapter 3-Catalyst Characterization. John Wiley \& Sons, New Jersey (2009)

13. Baghalha, M., Khosravian Gh, H., Mortaheb, H.R.: Kinetics of platinum extraction from spent reforming catalysts in aqua-regia solutions. Hydrometallurgy 95, 247-253 (2009). doi:10.1016/j. hydromet.2008.06.003

14. Roque-Malherbe, R.M.A.: Adsorption and diffusion in nanoporous materials. CRC Press, Boca Raton (2007)

15. Herreros, J.M., Gill, S.S., Lefort, I., Tsolakis, A., Millington, P., Moss, E.: Enhancing the low temperature oxidation performance over a Pt and a Pt-Pd diesel oxidation catalyst. Appl. Catal. B Environ. 147, 835-841 (2014). doi:10.1016/j. apcatb.2013.10.013

16. DieselNet: Catalyst fundamentals. Revision 2000.11a available at https://dieselnet.com (2000)

17. Winkler, A., Ferri, D., Hauert, R.: Influence of aging effects on the conversion efficiency of automotive exhaust gas catalysts. Catal. Today 155, 140-146 (2010). doi:10.1016/j.cattod.2008.11.021

18. Lide, D.R.: CRC handbook of chemistry and physics, 84 th edition. Taylor \& Francis, Boca Raton (2003)

19. Gélin, P., Primet, M.: Complete oxidation of methane at low temperature over noble metal based catalysts: a review. Appl. Catal. B Environ. 39, 1-37 (2002). doi:10.1016/s0926-3373(02)00076-0

20. Farrauto, R.J., Lampert, J.K., Hobson, M.C., Waterman, E.M.: Thermal decomposition and reformation of $\mathrm{PdO}$ catalysts: support 
effects. Appl. Catal. B Environ. 6, 263-270 (1995). doi:10.1016 /0926-3373(95)00015-1

21. Lefort, I., Herreros, J.M., Tsolakis, A.: Reduction of low temperature engine pollutants by understanding the exhaust species interactions in a diesel oxidation catalyst. Environ. Sci. Technol. 48, 2361-2367 (2014). doi:10.1021/es4051499

22. Hilliard, J.C., Wheeler, R.W.: Catalysed oxidation of nitric oxide to nitrogen dioxide. Combust. Flame. 29, 15-19 (1977). doi:10.1016 /0010-2180(77)90089-X 